\title{
1980-2011: Parkinson's Disease and Advance in Stem Cell Research
}

\author{
Lidia Cova $^{1}$ and Marie-Therese Armentero ${ }^{2}$ \\ ${ }^{1}$ Department of Neurology, Laboratory of Neuroscience, \\ IRCCS Istituto Auxologico Italiano, Milan \\ ${ }^{2}$ Laboratory of Functional Neurochemistry, Interdepartmental \\ Research Centre for Parkinson's Disease, IRCCS \\ National Institute of Neurology C. Mondino, Pavia,
}

Italy

\section{Introduction}

Replenishing the depleted striatal dopamine stores with its immediate precursor, L-3,4dihydroxyphenylalanine (L-DOPA), to mimic dopamine-mediated neurotransmission still represents the gold standard for treating Parkinson's disease (PD). This pharmacological therapy offers immediate and effective symptomatic relief, especially at the early stages of the disease; it has, however, no influence on underlying neurodegenerative processes (Dass et al., 2006) that continue to evolve with time and are paralleled by a gradual loss of drug efficacy. As the disease progresses, steady adaptation, mostly continuous increase, of dopaminergic drug dosage is necessary, thereby favoring the emergence of considerable side effects, such as dyskinesia and psychiatric disturbances. The development of new treatments, or combination of treatments, able to relief motor symptoms and also delay or even halt the loss of dopaminergic neurons, has been and remains a fundamental issue for the development of innovative clinical strategies in PD. Transplantation of dopaminesecreting cells directly providing dopamine in the striatum, in particular, has been considered an adequate substitute to pharmacotherapy. However, although efficacy of this approach has now been asserted in numerous pre-clinical studies utilizing animal models of $\mathrm{PD}$, positive outcomes in clinical trials involving PD patients have been very variable and rather modest, and have been plagued by graft-induced dyskinesias. New sources for cell replacement and particularly stem cells (including induced patient-derived cells) may now provide advantages for future clinical therapies (Wakeman et al., 2011).

This chapter will briefly introduce rodent and nonhuman primate PD-like models commonly used in pre-clinical studies, which represent a fundamental platform for the preclinical evaluation of innovative interventions. We will then evidence the progresses accomplished since the first intracerebral transplantation of fetal neural tissue in PD patients describing the subsequent novel discoveries for the application of stem cell to pre-clinical PD models, and give an overview of ongoing cell-based therapeutic strategies. Thereafter, multiple issues connected to stem transplantation to efficiently contrast adverse effects of increased age will be reviewed including decrease of apoptosis related to tissue degeneration, requirement of correct graft integration in the host vascular and neural 
circuits, reduction of diffuse inflammatory response/oxidative stress and correct release of key growth factors. In addition we will discuss the emergence of novel biotechnologies that will, most likely, help unravel the complex interrelationship between transplanted stem cells and the host environment and will favor the development of novel therapeutic procedures readily applicable in PD patients.

\section{Animal models: A necessary pre-clinical tool for the development of innovative cellular therapy in PD}

Animal models represent a fundamental step in the attempt to elucidate gene-environment interactions and to define pathogenic mechanisms involved in the aetiology and progression of the neurodegenerative diseases. Most of the current knowledge on pathophysiology of PD originates from studies conducted on animal models of the disease, since animals and humans share several anatomical features (as shown in Figure 1). In addition, they represent the first essential pre-clinical platform for the evaluation of any targeted therapeutic intervention. Notably, subsequent clinical trials in small human cohorts remain essential for the development of efficient therapies able also to alleviate disability related non-motor symptoms (Meissner et al., 2011) which are currently underestimated in animal models (Dunnett and Lelos, 2010).
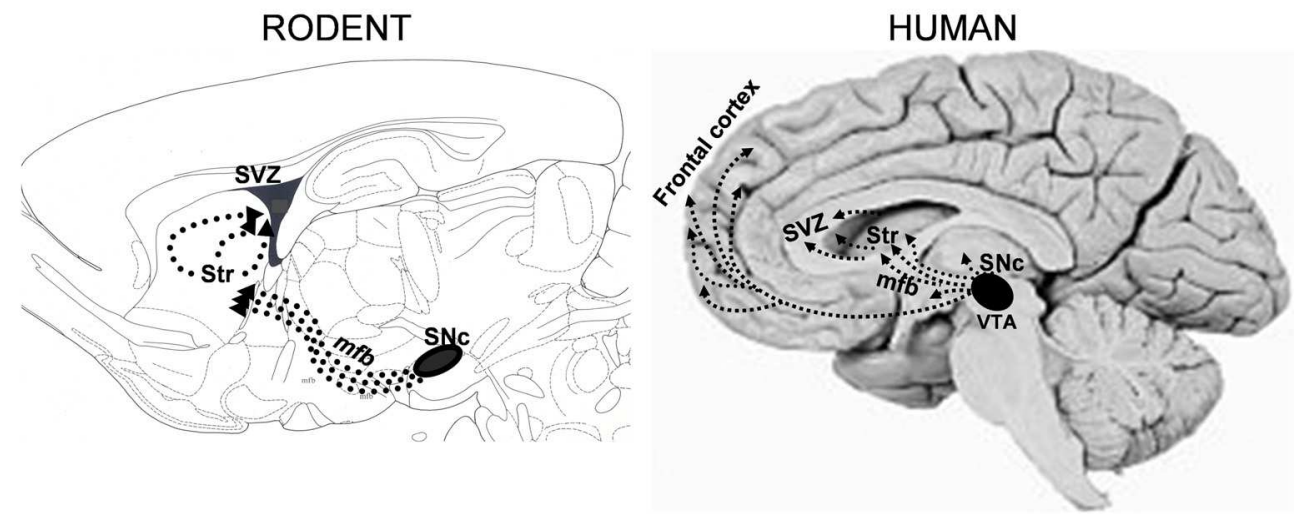

$\mathrm{Str}=$ striatum; $\mathrm{SVZ}=$ subventricular zone; $\mathrm{mfb}=$ median forbrain bundle; $\mathrm{SNc}=$ Substantia nigra; $\mathrm{VTA}=$ ventral tegmental area

Fig. 1. Anatomical comparison between mouse and human brains

The comparison between rodent (A) and human brain (B) enlightens their anatomical similarities and physiology. The connections between striatum, $\mathrm{SNc}$, and cerebral cortex in the human brain are indicated by dotted black lines and may correlate the simultaneous degeneration of these areas during disease onset and progression. Moreover, dopaminergic innervations of the striatum/SVZ (black dotted lines) could also explain reduction of adult brain neurogenesis both in PD patients and animal models.

PD models have been classically based on the administration of neurotoxins able to replicate some of the pathological and phenotypic features of the human disease both in rodents and 
primates. Toxins can be given systemically or intra-cerebrally, depending on the type of toxin used and animal specie involved, and mimic the selective degeneration of nigrostriatal neurons characteristic of the human disorder.

The classical systemic model is based on the injection of 1-methyl-4-phenyl-1,2,3,6tetrahydropyridine (MPTP), a toxin that selectively affects dopaminergic neurons and first recognized in the mid-1980's as the cause of marked parkinsonism in young drug users of Northern California (Langston et al., 1983). MPTP crosses the blood brain barrier and is transformed in its active metabolite, 1-methyl-4-phenylpyridinium ion (MPP+) that is then actively taken up by dopaminergic neurons of the substantia nigra pars compacta (SNc). Systemic administration of MPTP to nonhuman primates induces a parkinsonian phenotype closely resembling the human pathology. MPTP-treated monkeys have an excellent antisymptomatic response to dopaminergic drug treatment and develop motor complications linked to long term L-DOPA therapy (Kim et al., 2009). Concordantly, several pharmacological drugs currently applied to treated PD patients (i.e. dopamine agonists, amantadine, etc..) have been developed in this MPTP model (Fox et al., 2006). Alternative cell replacement strategies using various cell sources have been successfully performed indicating the technical feasibility of the model for future studies (Redmond et al., 2010; Serra et al., 2008). The large related costs and the difficulty to reliably standardize acute toxin administration to replicate most of the underlying mechanisms of a chronic progressive disorder form still represent major drawbacks and limit the use of this PD model in large scale studies (Fox and Brotchie, 2010). MPTP can also be systemically administered to mice but not rat, which are resistant, and several different experimental paradigms have been developed and used over time.

The prototypical intracerebral model is based on the local injection of 6-hydroxydopamine (6-OHDA) and was the first PD animal model ever generated (Ungerstedt, 1968). Six-OHDA is a hydroxylated analogue of dopamine and, similarly to MPTP, is actively taken up by dopaminergic neurons. The neurotoxin can be injected in the SNc, or into the medial forebrain bundle $(\mathrm{mfb})$ that conveys efferent fibers from the nigral cell bodies to the striatum (as shown in Figure 1) and causes massive and rapid anterograde degeneration of the nigrostriatal pathway. This procedure induces large nigral cell loss and striatal dopamine depletion $(90-100 \%)$. The neurotoxin can also be injected into the striatum; in this case rapid damage to striatal dopaminergic terminals is observed followed by a progressive loss of SNc neurons (50-70\% neuronal loss), which are secondarily affected through a "dying back" mechanism. This procedure has a slower time course compared to the intra-mfb injection and provides a progressive model of nigrostriatal degeneration, more similar to the gradual evolution of the neurodegenerative process of human PD. Importantly, injection of 6-OHDA is commonly carried out unilaterally, with the contralateral hemisphere serving as control, because of the high mortality rate associated with bilateral injection. The rat 6-OHDA model is commonly used in neuroprotective studies, both involving administration of novel pharmaceutical compounds or cell transplantation because it is i) cost-effective, ii) highly reproducible and iii) opened to articulate behavioural analyses (Redmond et al., 2010; Serra et al., 2008).

Numerous transgenic mouse models, that reproduce monogenic mutations observed in familiar forms of PD, have also been developed over the years. These models have not been discussed in this chapter as they typically display very low degree or even no nigrostriatal degeneration (for review see (Dawson et al., 2010)) and are not commonly used in stem cell transplantation experiments. 


\section{Neural tissue transplantation}

In 1987, the first clinical trials involving transplantation of human fetal mesencephalic tissues or xenotransplantation of fetal pig neural cells in humans were performed with the clear scope of replacing dopaminergic neurons lost during PD progression. Since then and overall, contradictory results have been observed, even among patient groups treated within the same centers (Bjorklund et al., 2003). Along with the observed poor graft survival (around 10\%; (Hagell and Brundin, 2001), a substantial subset of patients (15-56\%) developed dyskinesias (Freed et al., 2001; Hagell and Brundin, 2001; Olanow et al., 2003), while the presence of Lewy bodies in long-term implants, recently reported, suggests the possibility of a host-to-graft disease propagation (Kordower et al., 2008; Li et al., 2008; Mendez et al., 2008). Functional improvements, represented by reduction of symptoms (30\%-40\% improvement of the unified Parkinson's disease rating scale, motor score in the drug-free phase) have been clearly observed (Hagell and Brundin, 2001) even in the long term (Mendez et al., 2008; Piccini et al., 1999). Positive outcomes were dampened by enhanced microglial activation and disruption of blood brain barrier linked to surgical procedures (Olanow et al., 2003). Failures were also related to the scarcity, as well as heterogeneous composition of the donor tissue itself (Carlsson et al., 2009; Freed et al., 2001). Nonetheless, these first trials supported the feasibility of transplantation procedures as an alternative therapeutic approach in PD (Brundin et al., 2010; Olanow et al., 2003). Moreover, these first trials have enlightened critical parameters mandatory for successful tranplantations including: a) purity of cell preparation; b) correct localization of the graft in the host brain c) preference for reduced age of donor/host cells (whenever possible), d) limited extension of brain injury at the time of transplantation (early pathological phases), and e) appropriate time of grafting (in relation to disease onset) to maximize survival of endogenous dopaminergic neurons (Lindvall and Kokaia, 2009). Altogether, these observations have encouraged the search for alternative cell sources that need to be efficient, safe, and ethically acceptable (additional details on this debated/controversial topic can be found in (Kimmelman et al., 2009)).

\section{Stem cell therapy}

The scientific progresses in biological and cellular technologies have allowed a better conception of the mechanisms involved in cell development, and in particular of factors/conditions ruling Stem Cells (SCs) proliferation and differentiation. Essentially, SCs are undifferentiated multipotent cells capable of both self-renewal and generation of several differentiated functional cell types to preserve tissue homeostasis throughout the entire life span of an organism. Multiple properties of SCs, including their the ability to potentially generate an unlimited number of dopaminergic neurons under physiological conditions, make them attractive candidates for regenerative therapy (Dass et al., 2006).

Therefore, SCs have been increasingly recognized as a valuable replacement and/or supporting tool for PD wherein a well-characterized cell type is mainly affected. Cell therapy may be performed using either autologous (ideal from an immunologic perspective) or allogeneic tissue-specific differentiated cells. Transplantation of healthy SCs that have been collected, expanded and eventually pre-differentiated in vitro have been originally proposed as a feasible appealing neural-replacement strategy. To date, several fetal and adult SC lineages have been directly differentiated into multiple cellular types, including neural cells and dopaminergic phenotypes. These naïve SCs, or their induced neuronal 
progeny, have been successfully transplanted in animal models of PD granting significant behavioral improvements. Ideally, however, new therapies should not only aim at replenishing the depleted dopamine store, but should also allow rescue of neuronal terminals and soma both in striatum and SNc.

Innovative therapeutic strategy should also take advantage and enhance the plastic property of the adult Central Nervous System (CNS) to regenerate affected brain areas through the activation of endogenous neurogenesis following cell transplantation. To reach these targets, other known intrinsic properties of SCs have already been exploited. Indeed, the potential of SCs to restore injured tissues is not only related to their direct differentiation but also to their capacity to produce and release trophic factors that may in turn inhibit apoptosis, promote angiogenesis and even direct stimulation of host regeneration (Lindvall and Kokaia, 2009; Lindvall and Kokaia, 2010). Neuroprotection can also be enhanced by transplanting SCs engineered to express either tyrosine hydroxylase (TH), the rate-limiting enzyme of dopamine synthesis, or neurotrophic factors, such as glial cell-line derived neurotrophic factor (GDNF), the most potent survival factor for degenerating dopaminergic neurons. Grafting of engineered SCs in this case provides a substantial reservoir allowing the unlimited supply of the required substance without the requirement of invasive injection pumps, as detailed below. Several SC types have already been transplanted in PD animal models yielding interesting but variable results (Wakeman et al., 2011).

SCs can be efficiently derived from early stage embryos (pluripotent SCs with unlimited potential to differentiate) or from committed resident tissues (multipotent SCs with restricted potential to differentiate). Interestingly almost all organs arising from endodermal, mesodermal and ectodermal germ layers can originate both fetal and adult SCs (i.e. amniotic/cord blood and tissue derived SCs). Regardless of their origin SCs could physiologically repair damaged tissues after intense injuries also promoting angiogenesis and neurogenesis processes, essential for CNS development and regeneration (Lindvall and Kokaia, 2010).

\subsection{Embryonic stem cells}

Embryonic Stem cells (ES) are derived from the inner cell mass of pre-implantation embryos and are a source of pluripotent cells, as they are able to differentiate into all adult cell types. Once established, the pluripotent ES cells can be maintained under defined culture conditions, but can also be induced to terminally differentiate into a specific lineage (Bibikova et al., 2008). ES cells may potentially give rise to an infinite number of dopaminergic neurons that may be subsequently transplanted in depleted brain areas either in animal models of PD or even in patients (Lindvall and Kokaia, 2009). A particular emphasis has been posted on the validation of reliable methods for differentiation of ES cells towards midbrain dopaminergic neurons with a high survival index following transplantation (Hwang et al., 2010). Several protocols, characterized by presence of different feeder cell layers (i.e. bone marrow stromal cells, (Perrier et al., 2004) or astrocytes (Roy et al., 2006)) coupled to morphogen/growth factor exposition, have been developed. Transplantation of these in vitro-differentiated cells has produced variable results and often gave rise to tissue overgrowth with formation of neuroepithelial tumors, probably linked to the presence of residual immature cells in the original grafts. To overcome uncontrolled proliferation within transplants, cell-sorting protocols have been applied to specifically isolate pure populations of ES-derived dopaminergic neurons. These procedures, however, selectively impaired neuron survival indicating that fundamental factors were lost in the negative fraction (Friling et al., 2009). 
Recently, epigenetic manipulation to force dopaminergic gene expression has been also exploited (Andersson et al., 2006). Following transplantation in parkinsonian rats, these differentiated cells integrated in the brain of the animals and significantly improved PDrelated behavioral stereotypies (Yang et al., 2010). Application of this methodology to clinical practice, however, remains unrealistic until well-standardized, tumor-free samples will be available. Additional protocols for induction of dopaminergic phenotypes in ES cells have been recently developed (Chambers et al., 2009; Cooper et al., 2010), but functional efficacy of these cells has not been tested in PD animal models yet. Moreover, their use is still limited by our scarce knowledge of the development and specification of midbrain dopaminergic neurons (Pruszak and Isacson, 2009). Altogether, all experimental studies performed so far, demonstrate that ES-derived dopaminergic neurons are still unable to efficiently survive in and innervate lesioned brain areas in animal models of PD without inducing the formation of tumors (Arenas, 2010). In addition, ES cells frequently carry aberrant chromosome content in relation to growth advantage (Meisner and Johnson, 2008). Finally, the therapeutic application of ES cells will necessarily require both animal cell- and serum-free conditions (Klimanskaya et al., 2005), still substantially limiting their standardized application in clinic (Gruen and Grabel, 2006).

\subsection{Induced pluripotent SCs}

Recently, induced Pluripotent SCs (iPS) have been derived from primary fibroblast cultures obtained from cutaneous biopsies of patients affected by neurodegenerative diseases (Kriks and Studer, 2009; Lindvall and Kokaia, 2009). This complex reprogramming sequence was performed by exogenous expression of specific transcription factors that allowed a cellular switch from an epigenome of reduced potency to one of pluripotency (Kiskinis and Eggan, 2010). The resulting iPS cells could then be differentiated into autologous, patient-specific non-mitotic cells, such dopaminergic neurons and glial cells, normally present only in the CNS, and generally only available post-mortem.

iPS cells present several advantages when compare to ES cells: 1) their possible autologous derivation (Park et al., 2008b), 2) the consequent lack of mandatory immunosuppressant therapy following transplantation, and 3) the absence of ethical concerns related to embryo disruption (Arenas, 2010). These derived and/or differentiated cells can be used as donor cells in transplantation paradigms and represent a valuable tool to dissect intrinsic pathological mechanisms or test new pharmacological approaches in samples not readily available from live patients (Abeliovich and Doege, 2009; Gunaseeli et al., 2011; Xu et al., 2010a). However, the use of oncogenes or retrovirus in the current iPS cell establishment protocol raises considerable safety concerns (Pasi et al., 2011). Indeed, iPS progenies show high propensity to form teratomas considerably restricting their potential use in cell therapy (Miura et al., 2009). Heterogeneity of iPS cell composition with variable levels of transgene expression overtime suggests a prudent approach for iPS application to clinical trials (Kiskinis and Eggan, 2010). Recently, alternative protocols that allow direct fibroblast reprogramming towards neurons without generation of pluripotent cells have been developed (Vierbuchen et al., 2010). An additional notable potential risk of autologous therapeutic reprogramming is linked to the possibility that unknown genetic factors, involved in the patient's disease, could also potentially lead to disease-related alterations of the transplanted cells in the long term (Hwang et al., 2010). Transplantation of committed neural cells selected from differentiated PD patient-derived iPS cells has been tested in a lesional rodent model of PD with some overall beneficial effects. Transplanted cells 
integrated into the striatum of parkinsonian rats and improved behavioral deficits for up to 8 weeks, although no noticeable dopaminergic innervation from grafted cells to the surrounding striatum was observed (Wernig et al., 2008). Recently, Hargus et al, showed that iPS-derived dopaminergic neurons can be implanted and survive, without signs of neurodegeneration or tumor formation, both in healthy and 6-OHDA lesioned rats (Hargus et al., 2010). Although the grafted cells sent proper projections to close and remote target areas, acquisition of the appropriate regional identity is still argued. A significant behavioral improvement related to high survival of the transplanted dopaminergic neurons was also reported in simple, but not in complex motor functions, that rely on functional connections between grafted and host cells. Therefore, whether these preliminary results can be successfully translated into human clinical studies still awaits more experimental data (Hanna et al., 2010). Additional long-term studies will be necessary to recreate the correct pathophysiological conditions before validation of this model as an alternative cell-based therapy in PD (Kiskinis and Eggan, 2010). It has been hypothesized that an effective therapeutic effect following transplantation requires the survival of at least $10^{5}$ electrophysiologically active dopaminergic cells, appropriately contacting and reinnnervating striatum, without tumor formation (Arenas, 2010). Nevertheless, iPS cells could still be exploited for drug screening or as disease model to unravel pathological cascades in PD (Xu et al., 2010a). An important draw back in the clinical application of iPS cells also resides in the elevated production costs of personalized iPS. The establishment of centralized iPS cell bank(s) has been proposed to insure that fibroblast-derived dopaminergic neurons for transplantation are obtained following the Good Manufacturing Practice (GMP) guidelines for clinical trial materials.

\subsection{Patient-derived Neural SCs}

An innovative cellular approach is based on patient-derived neural stem cells (NSC) obtained from biopsies of their olfactory mucosa biopsies. This procedure allows the derivation of large quantities of NSC that can be grown in vitro as floating differentiable neurospheres. The cells bear significant pathological, disease-specific alterations in gene and protein expression, as well as cell function, such as dysregulated mitochondrial function, oxidative stress and xenobiotic metabolism (Matigian et al., 2010). Direct exploitation of these patient-derived neural cells will help obtain new insights in specific candidate genes and cell pathways for future studies of brain disease. These SCs could partially overcome the lack of appropriate animal models, faithfully recapitulating all of the clinical and pathological phenotypes of the disease, to study the mechanisms underlying PD as well as to develop translational drug development (Schule et al., 2009). In addition, these cells have a considerable advantage over ES and iPS cells, as they do not require reprogramming, and represent an important tool, with a considerable translational impact to all complex diseases. Moreover, biopsies easily obtained from neural tissues could supply new biomarkers for monitoring disease progression in PD patients. Development of such biomarkers represents a necessary step for the accomplishment essential for quality research and clinical trials (Lebouvier Thibaud et al., 2010). Derivation of patient NSC encompasses all the specific gene-environment interactions which appear fundamental along ageing process in sporadic neurological as well as psychiatric disorders (Matigian et al., 2010). Patient derived SCs are particularly intriguing for their potential in cell therapy and regenerative medicine: they may provide novel insights for the development of therapeutic strategies, aiming to contrast the neurodegenerative processes of PD. The discovery of the 
specific molecules involved in these biological events could also shed light on new pharmacological disease-modifying treatments and novel potential targets, readily applicable to patients (Schule et al., 2009).

Anyway, a cautionary approach is required, since this invasive methodology still requires development of standardized, validated protocols able to reach a structure (olfactory mucosa) not accessible to routine biopsies (Parkkinen et al., 2009)].

\subsection{Multipotent adult stem cells}

Multipotent SCs have been identified within specific niches in most adult tissues including bone marrow, muscle, brain, heart and liver. Adult SCs that comprise fetal, amniotic, umbilical cord blood, placental, as well as tissue derived SCs (i.e. hematopoietic, neural, mesenchymal, skin SCs) are less abundant and proliferative, and possess limited potential to differentiate compared to ES cells. A key added value of adult SCs, however, is their potential use in autologous therapies, in which cells can be harvested and used within the same patient, thus avoiding the ethical concerns and risks linked to ES cells (Fricker-Gates and Gates, 2010). The ideal procedure involves isolation of SCs from tissues and their preservation in standardized stocks at centralized unit banks for long term storage and subsequent transplantation into patients upon request (Arenas, 2010) (see Figure 2). In this section we will summarize the actual state of the art and deadlocks regarding three main SC lineages: hematopoietic (HSC), mesenchymal (MSC) and neural (NSC).

Bone marrow resident HSC and MSC constitute two important cell sources for pre-clinical transplantation. HSC can be easily derived from autologous/allogeneic bone marrow or peripheral blood, and are routinely used in transplantation procedures for the treatment of several immuno-deficient/autoimmune diseases, as well as hematopoietic disorders, to reconstitute peripheral cell lineages (i.e. leukocytes, erythrocytes, etc). Recently, transplantation of HSC, engineered to release $\mathrm{TH}$, has been reported to produce significant therapeutic effects in PD rats (Zhang et al., 2008).

A large body of data on the application of MSC in cell therapy can be found in literature; MSC are non-hematopoietic, multipotent cells which arise from the stromal structures of the bone marrow and are preserved in adults (Picinich et al., 2007). MSC can generate mature endothelial cells and several mesenchymal cell lineages including osteoblasts, chondrocytes, adipocytes and myoblasts (Liu et al., 2009). Several publications report efficient and multidisciplinary protocols for their differentiation, in vitro, towards dopaminergic neurons (Heinrich et al., 2009; Kitada and Dezawa, 2009) even including the use of lentiviral vectors to induce TH expression (Barzilay et al., 2009). Positive outcomes in acute hypoxic-ischemic damages have been obtained utilizing MSC isolated from several stem sources, such as human placenta and amniotic fluid, either naïve (Cipriani et al., 2007) or following neural differentiation (Park et al., 2011). Positive results, such as stability and physiology of the correct phenotype in vitro (Thomas et al., 2011) and in vivo after transplantation of MSC in animal models of PD (Shetty et al., 2009), as well as in PD patients (Venkataramana et al., 2010) have been reported. The long-term fate of grafted cells is still, however, matter of debate (Schwarz and Storch, 2010; Schwarz and Schwarz, 2011) and application of cell therapy to a chronic degenerative disease like PD appears rather complex. Successful outcomes of transplantation can be influenced by multiple factors largely dependent on the source and type of SCs adopted. For example, it has been reported that neural differentiation of MSC is required before intrastriatal transplantation in PD rats to observe a graft-dependent improvement of motor deficits (Levy et al., 2008). Transplantation of naïve 
human umbilical vein-derived dopaminergic-like cell in a rat model of PD did not improve motor dysfunction, and required administration of a neurotrophin, nerve growth factor, to induce substantial recovery ( $\mathrm{Li}$ et al., 2010a). Lineage negative cells from umbilical cord blood efficiently gave rise to neuronal cells and oligodendrocytes in vitro (Chua et al., 2009) while lineage specific (cKit+) amniotic-derived SCs fail to acquire a dopaminergic phenotype after epigenetic stimuli both in vitro and in an animal model of PD (Donaldson et al., 2009). Concordantly, upon neuronal induction bone marrow-derived MSC downregulate markers of other lineages, but fail to differentiate into functional neurons (Thomas et al., 2011). The functional positive effects exerted by transplanted MSC in PD animal models, are still controversial on the basis of technical criticisms, strength of trial design or inconsistent experimental approaches (Meyer et al., 2010). MSC have a significant protective effect against dopaminergic cell loss both in vitro and in vivo (Park et al., 2008a), but whether this results from true dopaminergic neuron replacement and how the cells actually induced functional improvement are still far from being clarified (White, 2011). Thus, before MSC can be considered a reliable source for clinical replacement of dopaminergic cells, their ability to transdifferentiate terminally towards a neuronal lineage needs to be resolved and their mechanism of action following transplantation needs to be elucidated (Schwarz and Storch, 2010).

Another promising source of SC is represented by NSC, that can be derived from various source including the subventricular zone (SVZ), ES, umbilical cord blood, MSC, fetal brain as well as spinal cord, and grown in suspension as floating clusters (neurospheres) (Meyer et al., 2010). NSC can restore functions lost during ageing, and both migrate towards and repair neurological damages, exerting positive influence on the surrounding cells, including dysfunctional neurons (Ourednik et al., 2002). Autologous transplantation of in vitroexpanded cortical and subcortical tissue samples, obtained from a PD patient during a neurosurgical procedure, produced long lasting motor improvements (Lévesque et al., 2009). Interestingly, fetal and adult NSC possess comparable intrinsic therapeutic potential in terms of cell survival, integration and functional outcomes in a rat model of PD (Muraoka et al., 2008). However, albeit feasible, harvesting samples from patient remains an invasive procedure and is difficult to translate into a routine therapy. NSC do not give rise to dopaminergic neurons under physiological conditions, but several protocols have been optimized for their forced differentiation towards this lineage. Mimicking the procedures for dopaminergic differentiation from ES cells, a group has reported the differentiation of immature NSC into forebrain, but not midbrain (area A9), dopaminergic cells (Papanikolaou et al., 2008), while forced expression of Nurr1, a transcriptional factor specific for midbrain dopamine neuron development, induced dopaminergic neuron phenotype in NSC isolated both from SVZ and the white matter (Shim et al., 2007). The appearance of specific neuronal subtypes is not solely a direct consequence of external cues or the expression of neurotrophins but likely depends on the integrated temporal sequence of multiple factors that finally results in the correct neuronal phenotype. Regionalization and specification of the midbrain territory rely on a defined pattern of transcription factor expression and secretion of soluble molecules within the neuroectoderm in physiological conditions. This pattern is a composite process difficult to correctly recapitulate in vitro and has been only partially unraveled (Fricker-Gates and Gates, 2010). Interestingly, transplantation of NSC derived from MSC, using a complex protocol based on TH transfection and culture in media for differentiation, in 6-OHDA lesioned rats has been recently reported. Cell grafting induced significant behavioral improvements that were associated with partial preservation 
of dopamine content (Zou et al., 2010). A similar approach was applied to MPTP-lesioned parkinsonian rhesus monkeys; transplantation of $\mathrm{TH}$ - transfected bone marrow cells in the caudate nucleus and SNc improved both PD-related alterations in glucose metabolism and dopamine transport with an overall recovery of behavioral symptoms (Xu et al., 2010b). Similarly, allogeneic NSC modified to stably express and release the neurotrophic factor Neurotrophin-3 (NT-3), displayed enhanced dopaminergic neuron differentiation as well as migration distance, and induced the reinnervation in the neural circuitry coupled to functional recovery upon transplantation in 6-OHDA-treated rats (Gu et al., 2009). Recently, Murrell and colleagues proposed that dopaminergic neurons may be generated directly from adult olfactory SC of PD patients, similarly to Matigian et al (Matigian et al., 2010): in this paper the authors further demonstrated that differentiation of neural progenitor cells in dopaminergic-like neurons was able to correct behavioral asymmetry in the rat model of PD (Murrell et al., 2008).

Albeit these overall positive data, additional long term trials on the safety, efficacy, as well as further understanding of the biological mechanisms activated by graft procedures still need to be accomplished. So far, real functional integration between ectopically grafted SCderived dopaminergic neurons in the denervated striatum has been demonstrated only in organotypic cultures of wild type mouse striatum (Tonnesen et al., 2011). Therefore, studies aimed at the characterization of the molecular basis of the integration in/differentiation of (genetically modified) NSC, and their progeny, within the dopaminergic network deserve further extensive development. Finally, the invasive intracerebral procedure required for the isolation of NSC as a possible SC source in the treatment of neurodegenerative diseases still remains a major draw back for their clinical application.

It is also important to notice that all the three SC lineages (HSC, MSC and NSC) can be obtained from bank-stored umbilical cord blood and amniotic/placenta cells, while only HSC and MSC can be easily isolated from autologous peripheral blood, thus amplifying the potential SC pool for clinical or experimental settings without ethical concerns (Figure 2).

\section{Stem Cell \& Neuroinflammation}

Recent discoveries regarding the role of the immune system in brain damage coupled to the development of new technologies to manipulate the immune response make immunotherapies an attractive target to treat neurological diseases (Tansey and Goldberg, 2010). In the past decade, neuroinflammation has emerged as an important substrate for PD (Brochard et al., 2009). Several epidemiologic studies have reported an inverse correlation between the chronic assumption of non-steroidal anti-inflammatory drugs and the risk of developing PD (Chen et al., 2003). Unrestrained widespread neuroinflammation emerges during the early phases of the neurodegenerative process both in PD patients and in animal models of the disease (Whitton, 2010) and significant evidence demonstrates that neuroinflammatory processes participate in PD pathophysiology. Gliosis and lymphocyte infiltration associated with production of soluble factors - potentially protective or toxic are consistently reported in parkinsonian animals and PD patients (McGeer et al., 1988; McGeer and McGeer, 2004; McGeer and McGeer, 2008) Most studies in animal models of PD have demonstrated that efficient neuroprotective strategies that decrease nigrostriatal degeneration also consistently reduce associated neuroinflammatory processes, and viceversa, underlying the fundamental link between neuroinflammation and neurodegeneration. Recent data have also supported the idea that a reduction in the levels of anti-inflammatory 
factors itself can further enhance vulnerability of dopaminergic neurons to apoptosis in a neurodegenerative environment (Barnum and Tansey, 2010; Lu et al., 2010; Maguire-Zeiss and Federoff, 2010). Furthermore, it has been recently suggested that pro-inflammatory cytokines exert a negative impact on neuronal differentiation, while anti-inflammatory cytokines facilitate neurogenesis (Mathieu et al., 2010) and neuronal migration towards appropriate targets (Das and Basu, 2008). These data clearly indicate that pro- and antiinflammatory responses must be strictly balanced to prevent the potential detrimental effects of prolonged or unregulated inflammation on vulnerable neuronal populations (Lee and Park, 2009). It has been shown that outcome of the transplantation of ES-derived THpositive cells in an MPTP mouse model of PD is strictly dependent on the concomitant administration immunosuppressive treatment (Toriumi et al., 2009) that significantly improved survival and integration of grafted SC overtime.

Noteworthy, inflammation, which has long been considered as thoroughly disastrous for brain repair, is now known to produce some positive effects on stem/progenitor cell recruitment/survival by growth factor signalling and the secretion of chemoattractant cytokines (Cayre et al., 2009; Mathieu et al., 2010). Conversely, inflammatory mediators, such as nitric oxide (NO) and reactive oxygen species (ROS), can contribute to neurodegeneration by triggering aberrant protein modifications with consequent misfolding and loss of function (Vicente Miranda and Outeiro, 2010). Application of MSC, a particular SC lineage described above (section 4.4), that knowingly possess significant inherent immunomodulatory properties, opens new perspective for cell transplantation in PD. MSC can interactively act on their environment through the local/distal release of trophic factors, as well as on the activation of immune response by means of cell contact-dependent mechanism and modulation of noxious inflammatory components (Lee and Park, 2009). MSC were proven to effectively protect dopaminergic neurons from lipopolysaccharide (LPS)-induced neurotoxicity, both in vitro and in vivo, via anti-inflammatory mechanisms involving the modulation of microglial activation (Kim et al., 2009). Microglia, in turn are responsible for the correct phagocytic clearance following injury, thus facilitating the reorganization of neuronal circuits and triggering repair (Neumann et al., 2009). Notably, aside from immunomodulation, the complex network of biological mechanisms activated by MSC transplantation includes their homing to the SNc, substitution of dopaminergic neurons, modulation of apoptosis and modification of ubiquitin-proteasome function. Concordantly, at the moment, MSC constitute the most attractive and autologous candidate disease modifying strategy for PD and other neurodegenerative disorders (Karussis et al., 2008).

\section{Neurorepair/Neurogenesis}

The nigrostriatal network is highly organized and finely regulated in relation to specific functions and circumstances. As a consequence, restoring lost dopaminergic neurons does not necessarily coincide with correct reconstruction the pathway (Obeso et al., 2008). Partial maintenance of neuron survival and function in the SNc within the neurodegenerative environment, following transplantation of SCs could, per se, potentially translate in significant therapeutic outcomes. Substantial neuroprotective effects against dopaminergic depletion have been observed, for example, after transplantations of naïve, undifferentiated SCs such as adult adipose-derived adult stromal cells (McCoy et al., 2008), human NSC (Yasuhara et al., 2006) or human MSC (Blandini et al., 2010) in 6-OHDA lesioned rats. 
Similarly, neuroprotection was evident following grafting of human MSC in an animal model of progressive parkinsonism (Park et al., 2010; Park et al., 2008a). In an interesting approach, transplantation of genetically engineered NSC, in animal models of brain tumor or injury, could served as incessant sources of secreted therapeutic agents (neuroprotective or tumoricidal) playing the role of biological minipumps (Chen et al., 2007). This procedure could readily be applicable to neurodegenerative diseases, including PD. As already described for neuroinflammation, the complex interactions between grafted SCs and endogenous surrounding cells can reciprocally influence outcome of transplantation both through direct interconnections (adherent junctions) or long distance mediations (release of soluble factors) (Boucherie and Hermans, 2009). In Amyotrophic Lateral Sclerosis for example, non-neuronal neighboring cells, including astrocytes, can drastically enhance neuronal survival (Nagai et al., 2007). Concordantly, in PD, glial cells play a critical role in homeostatic mechanisms that promote neuronal survival through release of an array of proand anti-inflammatory cytokines, anti-oxidants and neurotrophic factors within the microenvironment of the brain (L' Episcopo et al., 2010). Interestingly, grafting of MSC differentiated towards astrocyte-like phenotypes resulted in relevant improvements of motor impairment in 6-OHDA lesioned rats in the absence of dopaminergic differentiation (Bahat-Stroomza et al., 2009). Similarly, naïve MSC transplanted in the striatum of 6-OHDA lesioned animals acquired a glial-like phenotype and significantly reduced the toxininduced neurodegeneration (Blandini et al., 2010).

Recent innovative approaches also include the use viral vectors to induce selected SC to produce/release specific neurotrophins possibly active in repairing/rescuing the degenerating nigrostriatal system. New protocols for efficient transduction of MSC allowing enhanced delivery of GDNF have been developed. Transplantation of the transduced cells in experimental PD resulted in the preservation of striatal TH immunoreactivity around the graft (Moloney et al., 2010). Similarly, GDNF- and Brain Derived Neurotrophic Factor (BDNF)-secreting MSC transplanted in 6-OHDA lesion rats improved behavioral deficits, typically detected in these animals (Sadan et al., 2009). Human neural progenitor cells that had been genetically modified to release GDNF, readily survived without tumor formation, following the intrastriatal transplantation into the brain of aged monkeys (Behrstock et al., 2006). A comparative study with non human primate has evidenced that the striato-nigral axon-transport is also compromised in advanced PD patient potentially limiting the regular retrograde transport of factors towards affected neuronal bodies in the SNc (Bartus et al., 2011). These therapeutic strategies may, therefore, be applicable mainly to patients at an early stage of the disease when part of the nigrostriatal network is still spared and may be rescued. Different clinical approaches may be required as disease proceeds with the wide loss of dopaminergic neurons (Rascol, 2009).

Donor cells, to physiologically repair damaged neural circuitry using SC transplantation, must be able to survive in sufficient number, to differentiate into the appropriate cell type and to adequately support the host brain environment. To optimize functional recovery and minimize side effects, grafted SCs should be able to functionally integrate in and be regulated by the host brain. Outcome of transplantation may be directly affected by time of grafting and cell number (Darsalia et al., 2011). Correlation between cell amount and therapeutic effects has, for example, been demonstrated for naive MSC that dosedependently and regionally sustained the survival of striatal/nigral dopaminergic terminals and enhanced neurogenesis, following intrastriatal transplantation in parkinsonian rats (Blandini et al., 2010; Cova et al., 2010). Among the pathogenetic mechanisms involved in 
PD a role of reduced neurogenesis has been suggested (Geraerts et al., 2007). The SVZ, one of the two neurogenic zones region located in the lateral wall of the ventricles that maintains the largest pool of proliferating cells in the mature mammalian CNS, receives organized projections from the SNc. These efferent projections can influence precursor cell proliferation in both adult animal (Baker et al., 2004; O'Keeffe et al., 2009a) and primate models (Freundlieb et al., 2006), probably through dopamine-induced release of Epidermal Growth Factor in the SVZ (O'Keeffe et al., 2009b). Dopaminergic denervation within SVZ causes a reduced rate of neural precursor mitosis and abridged neuronal maturation in the long term, a phenomenon common among PD patients (Hoglinger et al., 2004) and toxininduced animal models of PD (Aponso et al., 2008; He et al., 2006; He et al., 2008; Winner et al., 2009; Winner et al., 2006).

\section{Possible SC sources for cell therapy in PD}

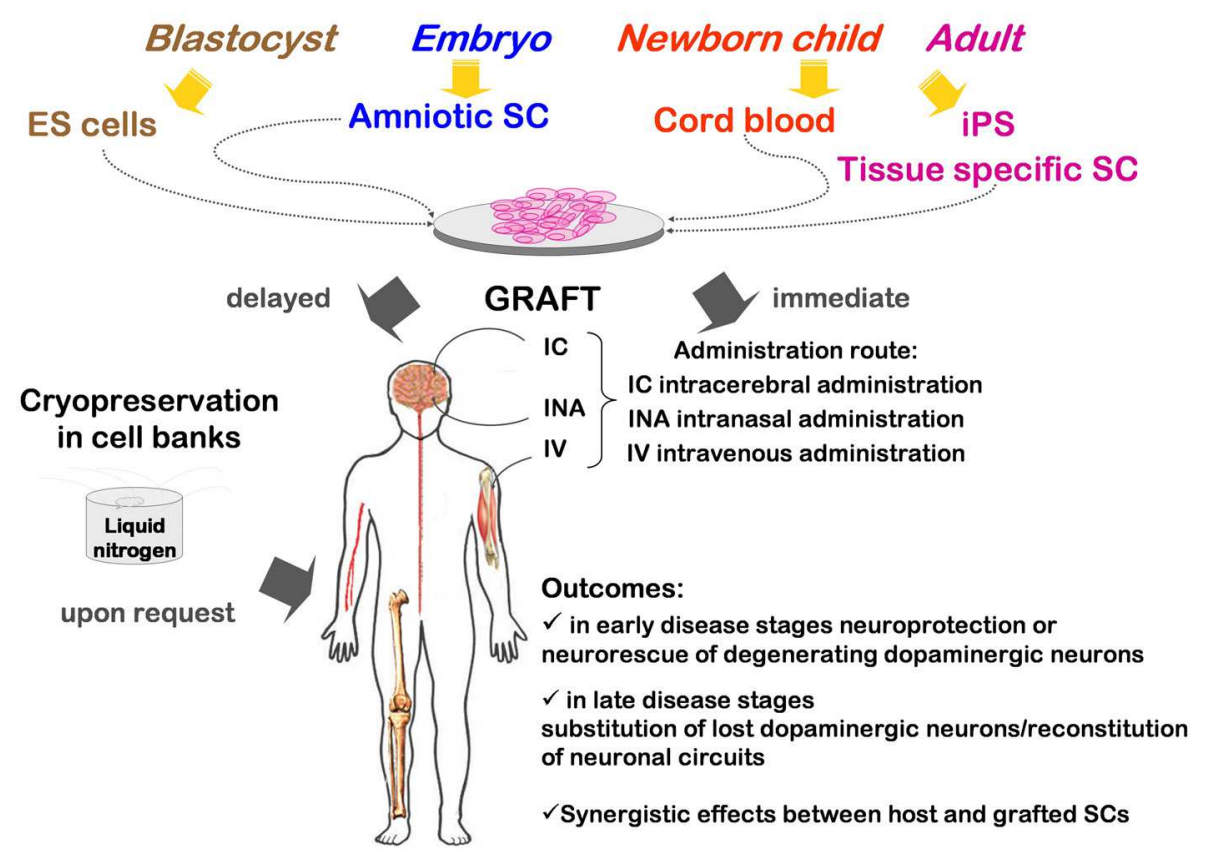

Fig. 2. Schematic flow chart for cell therapy in PD

A clinical approach to PD therapy will require 1) SC isolation (possible from different sources) 2) their expansion in vitro 3) direct or delayed transplantation through alternative or multiple administration routes. Independently from SC type and injection site, the therapeutic outcomes will depend upon donor and host ages, extension of the neuronal degeneration and graft size. The possible reparative mechanisms exerted by SC transplantation comprise neuronal replacement, neuroprotection of residual dopaminergic neurons and stimulation of endogenous neurogenesis, which may variably contribute to observed behavioral and physiological improvements. In PD cell therapy all the manipulations involving SCs should be conducted following the GMP guidelines in the absence of serum or other animal components. 
Release of growth factor by grafted SC may influence adult neurogenesis and up-regulate self renewal and/or differentiation of adult host cells both under physiological and pathological conditions. Pre-clinical data suggest that modulation of endogenous neurogenesis may represent an alternative ways to slow down neuronal cell loss and possibly regenerate affected brain areas by modulation of endogenous neurogenesis (Geraerts et al., 2007; Okano et al., 2007). Administration of several growth factors (i.e. Transforming Growth Factor-a, BDNF and Fibroblast Growth Factor) in striatum enhanced neuronal differentiation within SVZ with overall improvements in murine behavior (Chiocco et al., 2007). Moreover, in the SNc pharmacological activation of dopamine receptor D3 with a selective agonist -7-hydroxy-N,N-di-n-propyl2aminotetralin- induced cell proliferation and maturation towards dopaminergic phenotype (Van Kampen and Eckman, 2006), thus suggesting the possible occurrence of adult neurogenesis in this region under the pathological conditions in PD (Arias-Carrion et al., 2009). Presence of neurogenesis in the SNc suggests that disease progression may rely on the loss of dopaminergic neurons as well as on the malfunctioning in their turnover. Possible efficacy of orthotopic dopaminergic neurogenesis in PD has been questioned for a long time (Hermann and Storch, 2008), but transplantation experiments have indicated that several SC types, including neural precursors (Arias-Carrion et al., 2006; Madhavan et al., 2009) and MSC (Cova et al., 2010), can significantly support endogenous neurogenesis during the degenerative process in animal models of PD (Hess and Borlongan, 2008). Neurogenesis has been confirmed in SVZ of human brains (Curtis et al., 2007), but its physiological role is still uncertain (Zhao et al., 2008). Similarly, the existence of an improved neuronal reconstruction in the basal ganglia of the human PD brain (Yoshimi et al., 2005) is still a matter of debate. The reasons for decreased neurogenesis observed with aging and in pathological states may be related to an intrinsic inability to respond to the proliferative stimulation in the neurogenic niche, a reduction in the number of proliferative SC number, or the presence of activated microglia and neuroinflammation (Russo et al., 2011). Therefore, unraveling the localization as well as the degree of neurogenesis rate in human brains, together with the discovery of the specific molecules involved in these biological events, could lead to the discovery of new pharmacological disease-modifying treatments and novel potential targets, readily applicable to PD patients (Lindvall and Kokaia, 2010). Finally, it appears realistic to combine the synergistic effects between exogenous and endogenous SC actions to obtain cues on potential mechanisms involved in the noxious effects of neurodegeneration in PD as possible targets for clinical therapy (see Figure 2) (Madhavan and Collier, 2010).

\section{Stem cell transplantation: Delivery method and timing}

To date different SC types, as well as route of cell administration have shown efficacy in animal models. Two main routes have been generally used for SC delivery: intracerebral and intravascular. The first one is a stereotaxic transplantation of cells into the brain. Given, in PD, that brain damage principally occurs in both striatum (dopaminergic terminals) and $\mathrm{SNc}$ (neuronal soma), the best transplantation site, that would provide the most efficient and widest SC engraftment, is unknown. Nowadays, striatal administration of SCs is the most common approach for pre-clinical trials in PD (Blandini et al., 2010; Yasuhara et al., 2006; Zhu et al., 2009), although SC transplantation in $\mathrm{mfb}$ is also feasible (Gu et al., 2009). Gu and colleagues showed that double injection of NT-3 transfected NSC in mfb and ventral 
tegmental area of parkinsonian rats generates new $\mathrm{TH}$ positive cells in these areas with relevant behavioral and functional recovery (Gu et al., 2009).

Although the intracerebral route has provided a large panel of positive results in animal models and has allowed a better understanding of mechanisms underlying disease pathology, independently of the graft site, an outsized dilemma still resides in its invasive nature. To bypass this concern intravascular administration has also been undertaken. Intravenous administration of MSC after in 6-OHDA lesioned rats yields preservation of dopaminergic system and relevant behavioral improvements, although no transplanted SCs were observed in brain one month after injection (Wang et al., 2010). The intravenous administration route has obvious clinical advantages compared to intracerebral injection, yet evident efficient therapeutic benefits are fully dependent on the appropriate number of cells reaching the lesion sites. Concordantly, Wang et al have reported that the majority of SCs injected intravenously mostly dispersed in pulmonary tissue (Wang et al., 2010). This is in high contrast with the intracerebral route in which a large amount of cells are injected directly in or may easily migrate within the nearer lesion site. In 6-OHDA lesioned rats, the number of SCs still present at the site of injection, 4 weeks after transplantation, was proportional to the number of cells initially injected (Cova et al., 2010). Regardless of the delivery route adopted for transplantation, the biological mechanisms activated by SC graft rely both on cellular replacement and activation of the endogenous repair mechanisms coupled to neurorescue effects exerted on degenerating neurons (Lindvall and Kokaia, 2010). To date, no data from comparative studies between several administration routes (e.g., intrastriatal, intraventricular, and intravenous injections) of SC delivery in PD patients are available, although open labeled clinical trials with stereotaxic surgery have been already conducted (Venkataramana et al., 2010). An interesting clinical approach by multiple administration routes for the treatment of spinal cord injuries has just been developed. Such strategy induces noteworthy with improvements of the life quality for patients (Geffner et al., 2008) and could be very positively applied to chronic degenerative diseases such as PD.

Recently, an innovative alternative route for SC administration via a intranasal drop has been developed in an animal model of PD. MSC delivered into rat nostrils were found to migrate to lesion brain areas where they survived for at least 6 months (Danielyan et al., 2011). In these animals striatal dopamine levels were increased and motor functions improved up to $68 \%$ of values observed in control animals (Danielyan et al., 2011). This administration route appears safe and could potentially be repeated overtime in a given patients. The intranasal procedure could avoid problems related to surgical implantation of SCs, although the positive outcomes need to be further confirmed before any clinical applications.

Future therapeutic trials should also evaluate how the time point at which SC transplantation is performed, with respect to the cerebral insult, may influence efficacy of the procedure: earlier cell grafts may provide effective neuroprotection to degenerating neurons but the hostile environment may endanger their long-term survival by spreading disease hallmarks (Kordower et al., 2008; Li et al., 2008; Mendez et al., 2008). In principle, a time interval sufficient to allow in vitro expansion of autologous SCs, would obviously be desirable both from a practical and clinical perspective. On the other hand, transplantation at later disease stages, when cell loss is almost complete, will mainly aim at replacing lost dopaminergic neurons and will certainly be affected by the reduced expression of homing signals secreted in degenerative brain tissues. Conversely, transplantation at early stage will mostly rely on rescue and regeneration of surviving neurons. For CNS repair, 
transplantation of proliferating progenitors cells, whose fate is less predictable since they are more proliferative than neurons, would face difficulties in sorting from stray pluripotent SCs, in the absence of specific markers. A clear trial design will necessarily need to take in account all these different biological mechanisms and, most importantly, will require the development of the appropriate biomarkers (Rascol, 2009) to follow disease progression.

The choice of a specific SC type and its state of differentiation, as well as the amount of cells and route of administration will depend on the experimental endpoints, keeping in mind that each one faces inherent problems connected to local control of immune rejection, final differentiation towards dopaminergic neurons and cytokine release distally. For example transplantation of ES cells can lead to tumor formation and systemic injection of SCs may result in dispersion of the cells in non-target tissues. Circulating HSC could participate in the regeneration of peripheral tissues/organs, but only if a sufficient number of SCs is activated. Finally, as clearly pointed out by Irving Weissman, any future SC clinical application in neurodegenerative diseases will need to respect the four thresholds of clinical effectiveness: 1) cell homing to the diseased or injured tissue 2) effective engraftment, not just fusion with host cells 3) physiological effectiveness 4) permanence overtime (Weissman, 2000).

\section{In vivo imaging and transplantation}

As mentioned above animal models of PD are fundamental tools to evaluate feasibility and potential of a given SC population. To date translation of results obtained in preclinical animal models of PD has been difficult. In particular, the effect and long-term survival of transplanted cells remains an open issue. The development of innovative imaging techniques, combined with the creation of reporter transgenic mice, has widen our understanding of some pathological mechanisms of the disease and allowed the identification of specific pharmacological targets (van Nuenen et al., 2009). Precise tracking of transplanted SCs through novel imaging techniques, as well as monitoring of engraftment efficiency directly in vivo allows the immediate correlation between beneficial effects and SC localization/amount (Lee et al., 2008). Genetic tags have and continue to help researchers and bioethicists to track transplanted cells overtime following their behavior and dispersion in tissues in animals. The simplest tag uses genetic recombination to introduce a fluorescent marker, such as green fluorescent protein, into a cell, but magnetic nanoparticles have also been proven to be helpful (Ferreira et al., 2008). Since cell therapy relies on SC involvement in physiological circuits their upshots could persist over a long time and should, therefore, be devoid of side effects. Homing, engraftment, cell fate, persistence and tumor formation of labeled SCs and their progeny needs to be carefully evaluated and could potentially be assessed using in vivo imaging. In complex neurodegenerative diseases, such as PD, grafted SCs or derived progenitor cells may protect residual neurons rather than replacing the degenerated ones. Therefore, tagged grafts could be easily characterized to determine if transplanted cells trigger endogenous mechanisms of repair or whether they directly replace lost cell populations. Successful application of magnetically-labeled mouse embryonic SCs to a rat model of PD coupled to the study of their diffusion up to 6 months post transplant has already demonstrated the feasibility and safety of this approach (Stroh et al., 2009). Imaging techniques are already used to study early and presymptomatic stages of PD (Wu et al., 2011) and effectively measures outcomes in clinical trials of neuroprotection demonstrate 
that it is a practical non invasive method extensible to all PD patients (Pavese et al., 2009). PET measurements of 6-(18F) fluorodopa (18F-FDOPA) uptake indicate nigrostriatal neuronal integrity and may provide a useful endophenotype for PD linkage studies (Kumakura and Cumming, 2009). Clinical benefits and graft viability of embryonic dopamine cell implantation have been followed by functional imaging for up to 4 years after graft in 33 patients, thus correlating motor improvements with increased 18FFDOPA uptake (Ma et al., 2010).

\section{Conclusions}

Gaining more information about the pathology of the disease, the probable behavior of the grafted cells, as well as the reciprocal interconnections between the transplants and the host environment in animal models will be useful to predict possible complications and undesirable side effects readily translatable to future clinical trials for PD patients (Li et al., $2010 \mathrm{~b}$ ). Caution needs to be adapted since xenograft models of disease in animals may not accurately predict the same response in humans due to inherent differences. However, preclinical data will help improve patient selection for future clinical trials, assess restoration of brain connectivity, and monitor inflammatory processes in the continuous search of novel therapeutic targets (Politis and Piccini, 2010). Moreover, targeted delivery of SCs through alternative routes could be easily compared in animal models. Concordantly, one objective of modern neuroimaging is to identify markers for clinical diagnosis, monitor the disease progression, define the exact SC placement and analyze the impact of long-term drug/cell therapy through the direct spatio-temporal visualization of SCs as well as their effect on disease progression in patients, using non invasive techniques (Lee et al., 2008). A successful SC therapy requires extensive knowledge on SC properties, appropriate harvesting, manipulation and apt implantation, but also subsequent graft monitoring in the long time to verify the permanence of reparative mechanisms (Nikolic et al., 2009). On the basis of these data, it may be possible to properly select SC type, administration timing and delivery route for specific disease entities, anatomic areas, and physiologic circumstances to obtain reproducible experimental results for the creation of effective clinical protocols (Lindvall and Kokaia, 2010).

Additionally, cell transplantation in animal is often performed before or contemporaneously to neurotoxin lesion. Further development of experimental models that more accurately recreate neurodegenerative conditions present in patients, in which treatment can only intervene when the degenerative process is overt and motor symptoms are manifest, is required. In particular, the creation of genetic animal models is becoming increasingly important to elucidate gene-environment interactions, define pathogenic mechanisms, and provide a platform for testing cell therapeutic interventions (Magen and Chesselet, 2010).

The development and validation of conventional pharmacological therapy for clinical use is a long process that usually requires at least a decade. Cell transplantation, which represents an advanced therapeutic strategy far more complex than any pharmaceutical compound, was introduced surprisingly early into the clinic. Although some positive effects have been observed in the pioneering clinical studies sufficient caution should be taken before this strategy can be "routinely" applied to PD patients in order to avoid complications that may set back the field. In particular, defining and validating a specific cell type that may be consistently used in transplantation procedures is still a milestone that needs to be achieved. Extensive interactions and communication between clinicians and pre-clinical scientists is 
mandatory to allow the constant fine-tuning of the design of therapeutic strategies for PD patients.

\section{References}

Abeliovich A, Doege CA. Reprogramming therapeutics: iPS cell prospects for neurodegenerative disease. Neuron 2009; 61: 337-9.

Andersson E, Tryggvason U, Deng Q, Friling S, Alekseenko Z, Robert B, et al. Identification of intrinsic determinants of midbrain dopamine neurons. Cell 2006; 124: 393-405.

Aponso PM, Faull RL, Connor B. Increased progenitor cell proliferation and astrogenesis in the partial progressive 6-hydroxydopamine model of Parkinson's disease. Neuroscience 2008; 151: 1142-53.

Arenas E. Towards stem cell replacement therapies for Parkinson's disease. Biochem Biophys Res Commun 2010; 396: 152-6.

Arias-Carrion O, Hernandez-Lopez S, Ibanez-Sandoval O, Bargas J, Hernandez-Cruz A, Drucker-Colin R. Neuronal precursors within the adult rat subventricular zone differentiate into dopaminergic neurons after substantia nigra lesion and chromaffin cell transplant. J Neurosci Res 2006; 84: 1425-37.

Arias-Carrion O, Yamada E, Freundlieb N, Djufri M, Maurer L, Hermanns G, et al. Neurogenesis in substantia nigra of parkinsonian brains? J Neural Transm Suppl 2009: 279-85.

Bahat-Stroomza M, Barhum Y, Levy YS, Karpov O, Bulvik S, Melamed E, et al. Induction of adult human bone marrow mesenchymal stromal cells into functional astrocyte-like cells: potential for restorative treatment in Parkinson's disease. J Mol Neurosci 2009; 39: 199-210.

Baker SA, Baker KA, Hagg T. Dopaminergic nigrostriatal projections regulate neural precursor proliferation in the adult mouse subventricular zone. Eur J Neurosci 2004; 20: 575-9.

Barnum CJ, Tansey MG. Modeling neuroinflammatory pathogenesis of Parkinson's disease. Prog Brain Res 2010; 184: 113-32.

Bartus RT, Herzog CD, Chu Y, Wilson A, Brown L, Siffert J, et al. Bioactivity of AAV2neurturin gene therapy (CERE-120): Differences between Parkinson's disease and nonhuman primate brains. Mov Disord 2011; 26: 27-36.

Barzilay R, Ben-Zur T, Bulvik S, Melamed E, Offen D. Lentiviral delivery of LMX1a enhances dopaminergic phenotype in differentiated human bone marrow mesenchymal stem cells. Stem Cells Dev 2009; 18: 591-601.

Behrstock S, Ebert A, McHugh J, Vosberg S, Moore J, Schneider B, et al. Human neural progenitors deliver glial cell line-derived neurotrophic factor to parkinsonian rodents and aged primates. Gene Ther 2006; 13: 379-88.

Bibikova M, Laurent LC, Ren B, Loring JF, Fan JB. Unraveling epigenetic regulation in embryonic stem cells. Cell Stem Cell 2008; 2: 123-34.

Bjorklund A, Dunnett SB, Brundin P, Stoessl AJ, Freed CR, Breeze RE, et al. Neural transplantation for the treatment of Parkinson's disease. Lancet Neurol 2003; 2: 43745. 
Blandini F, Cova L, Armentero MT, Zennaro E, Levandis G, Bossolasco P, et al. Transplantation of undifferentiated human mesenchymal stem cells protects against 6-hydroxydopamine neurotoxicity in the rat. Cell Transplant 2010; 19: 20317.

Boucherie C, Hermans E. Adult stem cell therapies for neurological disorders: benefits beyond neuronal replacement? J Neurosci Res 2009; 87: 1509-21.

Brochard V, Combadiere B, Prigent A, Laouar Y, Perrin A, Beray-Berthat V, et al. Infiltration of CD4+ lymphocytes into the brain contributes to neurodegeneration in a mouse model of Parkinson disease. J Clin Invest 2009; 119: 182-92.

Brundin P, Barker RA, Parmar M. Neural grafting in Parkinson's disease Problems and possibilities. Prog Brain Res 2010; 184: 265-94.

Carlsson T, Carta M, Munoz A, Mattsson B, Winkler C, Kirik D, et al. Impact of grafted serotonin and dopamine neurons on development of L-DOPA-induced dyskinesias in parkinsonian rats is determined by the extent of dopamine neuron degeneration. Brain 2009; 132: 319-35.

Cayre M, Canoll P, Goldman JE. Cell migration in the normal and pathological postnatal mammalian brain. Prog Neurobiol 2009; 88: 41-63.

Chambers SM, Fasano CA, Papapetrou EP, Tomishima M, Sadelain M, Studer L. Highly efficient neural conversion of human ES and iPS cells by dual inhibition of SMAD signaling. Nat Biotechnol 2009; 27: 275-80.

Chen H, Zhang SM, Hernan MA, Schwarzschild MA, Willett WC, Colditz GA, et al. Nonsteroidal anti-inflammatory drugs and the risk of Parkinson disease. Arch Neurol 2003; 60: 1059-64.

Chen HI, Bakshi A, Royo NC, Magge SN, Watson DJ. Neural stem cells as biological minipumps: a faster route to cell therapy for the CNS? Curr Stem Cell Res Ther 2007; 2: 13-22.

Chiocco MJ, Harvey BK, Wang Y, Hoffer BJ. Neurotrophic factors for the treatment of Parkinson's disease. Parkinsonism Relat Disord 2007; 13 Suppl 3: S321-8.

Chua SJ, Bielecki R, Wong CJ, Yamanaka N, Rogers IM, Casper RF. Neural progenitors, neurons and oligodendrocytes from human umbilical cord blood cells in a serumfree, feeder-free cell culture. Biochem Biophys Res Commun 2009; 379: 217-21.

Cipriani S, Bonini D, Marchina E, Balgkouranidou I, Caimi L, Grassi Zucconi G, et al. Mesenchymal cells from human amniotic fluid survive and migrate after transplantation into adult rat brain. Cell Biol Int 2007; 31: 845-50.

Cooper O, Hargus G, Deleidi M, Blak A, Osborn T, Marlow E, et al. Differentiation of human ES and Parkinson's disease iPS cells into ventral midbrain dopaminergic neurons requires a high activity form of SHH, FGF8a and specific regionalization by retinoic acid. Mol Cell Neurosci 2010; 45: 258-66.

Cova L, Armentero MT, Zennaro E, Calzarossa C, Bossolasco P, Busca G, et al. Multiple neurogenic and neurorescue effects of human mesenchymal stem cell after transplantation in an experimental model of Parkinson's disease. Brain Res 2010; 1311: 12-27.

Curtis MA, Eriksson PS, Faull RL. Progenitor cells and adult neurogenesis in neurodegenerative diseases and injuries of the basal ganglia. Clin Exp Pharmacol Physiol 2007; 34: 528-32. 
Danielyan L, Schafer R, von Ameln-Mayerhofer A, Bernhard F, Verleysdonk S, Buadze M, et al. Therapeutic efficacy of intranasally delivered mesenchymal stem cells in a rat model of Parkinson disease. Rejuvenation Res 2011; 14: 3-16.

Darsalia V, Allison SJ, Cusulin C, Monni E, Kuzdas D, Kallur T, et al. Cell number and timing of transplantation determine survival of human neural stem cell grafts in stroke-damaged rat brain. J Cereb Blood Flow Metab 2011; 31: 235-42.

Das S, Basu A. Inflammation: a new candidate in modulating adult neurogenesis. J Neurosci Res 2008; 86: 1199-208.

Dass B, Olanow CW, Kordower JH. Gene transfer of trophic factors and stem cell grafting as treatments for Parkinson's disease. Neurology 2006; 66: S89-103.

Dawson TM, Ko HS, Dawson VL. Genetic animal models of Parkinson's disease. Neuron 2010; 66: 646-61.

Donaldson AE, Cai J, Yang M, Iacovitti L. Human amniotic fluid stem cells do not differentiate into dopamine neurons in vitro or after transplantation in vivo. Stem Cells Dev 2009; 18: 1003-12.

Dunnett SB, Lelos M. Behavioral analysis of motor and non-motor symptoms in rodent models of Parkinson's disease. Prog Brain Res 2010; 184: 35-51.

Ferreira L, Karp JM, Nobre L, Langer R. New opportunities: the use of nanotechnologies to manipulate and track stem cells. Cell Stem Cell 2008; 3: 136-46.

Fox SH, Brotchie JM. The MPTP-lesioned non-human primate models of Parkinson's disease. Past, present, and future. Prog Brain Res 2010; 184: 133-57.

Fox SH, Lang AE, Brotchie JM. Translation of nondopaminergic treatments for levodopainduced dyskinesia from MPTP-lesioned nonhuman primates to phase IIa clinical studies: keys to success and roads to failure. Mov Disord 2006; 21: 1578-94.

Freed CR, Greene PE, Breeze RE, Tsai WY, DuMouchel W, Kao R, et al. Transplantation of embryonic dopamine neurons for severe Parkinson's disease. N Engl J Med 2001; 344: 710-9.

Freundlieb N, Francois C, Tande D, Oertel WH, Hirsch EC, Hoglinger GU. Dopaminergic substantia nigra neurons project topographically organized to the subventricular zone and stimulate precursor cell proliferation in aged primates. J Neurosci 2006; 26: 2321-5.

Fricker-Gates RA, Gates MA. Stem cell-derived dopamine neurons for brain repair in Parkinson's disease. Regen Med 2010; 5: 267-78.

Friling S, Andersson E, Thompson LH, Jonsson ME, Hebsgaard JB, Nanou E, et al. Efficient production of mesencephalic dopamine neurons by Lmx1a expression in embryonic stem cells. Proc Natl Acad Sci U S A 2009; 106: 7613-8.

Geffner LF, Santacruz P, Izurieta M, Flor L, Maldonado B, Auad AH, et al. Administration of autologous bone marrow stem cells into spinal cord injury patients via multiple routes is safe and improves their quality of life: comprehensive case studies. Cell Transplant 2008; 17: 1277-93.

Geraerts M, Krylyshkina O, Debyser Z, Baekelandt V. Concise review: therapeutic strategies for Parkinson disease based on the modulation of adult neurogenesis. Stem Cells 2007; 25: 263-70.

Gruen L, Grabel L. Concise review: scientific and ethical roadblocks to human embryonic stem cell therapy. Stem Cells 2006; 24: 2162-9. 
Gu S, Huang H, Bi J, Yao Y, Wen T. Combined treatment of neurotrophin-3 gene and neural stem cells is ameliorative to behavior recovery of Parkinson's disease rat model. Brain Res 2009; 1257: 1-9.

Gunaseeli I, Doss MX, Antzelevitch C, Hescheler J, Sachinidis A. Induced pluripotent stem cells as a model for accelerated patient- and disease-specific drug discovery. Curr Med Chem 2011; 17: 759-66.

Hagell P, Brundin P. Cell survival and clinical outcome following intrastriatal transplantation in Parkinson disease. J Neuropathol Exp Neurol 2001; 60: 741-52.

Hanna JH, Saha K, Jaenisch R. Pluripotency and cellular reprogramming: facts, hypotheses, unresolved issues. Cell 2010; 143: 508-25.

Hargus G, Cooper O, Deleidi M, Levy A, Lee K, Marlow E, et al. Differentiated Parkinson patient-derived induced pluripotent stem cells grow in the adult rodent brain and reduce motor asymmetry in Parkinsonian rats. Proc Natl Acad Sci U S A 2010; 107: 15921-6.

He XJ, Nakayama H, Dong M, Yamauchi H, Ueno M, Uetsuka K, et al. Evidence of apoptosis in the subventricular zone and rostral migratory stream in the MPTP mouse model of Parkinson disease. J Neuropathol Exp Neurol 2006; 65: 873-82.

He XJ, Yamauchi H, Uetsuka K, Nakayama H. Neurotoxicity of MPTP to migrating neuroblasts: studies in acute and subacute mouse models of Parkinson's disease. Neurotoxicology 2008; 29: 413-20.

Heinrich AC, Patel SA, Reddy BY, Milton R, Rameshwar P. Multi- and inter-disciplinary science in personalized delivery of stem cells for tissue repair. Curr Stem Cell Res Ther 2009; 4: 16-22.

Hermann A, Storch A. Endogenous regeneration in Parkinson's disease: do we need orthotopic dopaminergic neurogenesis? Stem Cells 2008; 26: 2749-52.

Hess DC, Borlongan CV. Stem cells and neurological diseases. Cell Prolif 2008; 41 Suppl 1: 94-114.

Hoglinger GU, Rizk P, Muriel MP, Duyckaerts C, Oertel WH, Caille I, et al. Dopamine depletion impairs precursor cell proliferation in Parkinson disease. Nat Neurosci 2004; 7: 726-35.

Hwang DY, Kim DS, Kim DW. Human ES and iPS cells as cell sources for the treatment of Parkinson's disease: current state and problems. J Cell Biochem 2010; 109: 292-301.

Karussis D, Kassis I, Kurkalli BG, Slavin S. Immunomodulation and neuroprotection with mesenchymal bone marrow stem cells (MSCs): a proposed treatment for multiple sclerosis and other neuroimmunological/neurodegenerative diseases. J Neurol Sci 2008; 265: 131-5.

Kim YJ, Park HJ, Lee G, Bang OY, Ahn YH, Joe E, et al. Neuroprotective effects of human mesenchymal stem cells on dopaminergic neurons through anti-inflammatory action. Glia 2009; 57: 13-23.

Kimmelman J, London AJ, Ravina B, Ramsay T, Bernstein M, Fine A, et al. Launching invasive, first-in-human trials against Parkinson's disease: ethical considerations. Mov Disord 2009; 24: 1893-901.

Kiskinis E, Eggan K. Progress toward the clinical application of patient-specific pluripotent stem cells. J Clin Invest 2010; 120: 51-9. 
Kitada M, Dezawa M. Induction system of neural and muscle lineage cells from bone marrow stromal cells; a new strategy for tissue reconstruction in degenerative diseases. Histol Histopathol 2009; 24: 631-42.

Klimanskaya I, Chung Y, Meisner L, Johnson J, West MD, Lanza R. Human embryonic stem cells derived without feeder cells. Lancet 2005; 365: 1636-41.

Kordower JH, Chu Y, Hauser RA, Freeman TB, Olanow CW. Lewy body-like pathology in long-term embryonic nigral transplants in Parkinson's disease. Nat Med 2008; 14: 504-6.

Kriks S, Studer L. Protocols for generating ES cell-derived dopamine neurons. Adv Exp Med Biol 2009; 651: 101-11.

Kumakura Y, Cumming P. PET studies of cerebral levodopa metabolism: a review of clinical findings and modeling approaches. Neuroscientist 2009; 15: 635-50.

L' Episcopo F, Tirolo C, Testa N, Caniglia S, Morale M, Marchetti B. Glia as a turning point in the therapeutic strategy of Parkinson's disease. CNS Neurol Disord Drug Targets 2010; 9: 349-72.

Langston JW, Ballard P, Tetrud JW, Irwin I. Chronic Parkinsonism in humans due to a product of meperidine-analog synthesis. Science 1983; 219: 979-80.

Lebouvier Thibaud, Maddalena Tasselli, Sébastien Paillusson, Hélène Pouclet, Neunlist M, Derkindere aP. Biopsable neural tissues: toward new biomarkers for Parkinson's disease? . Frontiers in Psychiatry 2010; 1: doi: 10.3389/fpsyt.2010.00128

Lee PH, Park HJ. Bone marrow-derived mesenchymal stem cell therapy as a candidate disease-modifying strategy in Parkinson's disease and multiple system atrophy. J Clin Neurol 2009; 5: 1-10.

Lee Z, Dennis JE, Gerson SL. Imaging stem cell implant for cellular-based therapies. Exp Biol Med (Maywood) 2008; 233: 930-40.

Lévesque MF, Neuman T, Rezak M. Therapeutic Microinjection of Autologous Adult Human Neural Stem Cells and Differentiated Neurons for Parkinson's Disease: Five-Year Post-Operative Outcome. The Open Stem Cell Journal 2009; 1: 20-29.

Levy YS, Bahat-Stroomza M, Barzilay R, Burshtein A, Bulvik S, Barhum Y, et al. Regenerative effect of neural-induced human mesenchymal stromal cells in rat models of Parkinson's disease. Cytotherapy 2008; 10: 340-52.

Li JY, Englund E, Holton JL, Soulet D, Hagell P, Lees AJ, et al. Lewy bodies in grafted neurons in subjects with Parkinson's disease suggest host-to-graft disease propagation. Nat Med 2008; 14: 501-3.

Li M, Zhang SZ, Guo YW, Cai YQ, Yan ZJ, Zou Z, et al. Human umbilical vein-derived dopaminergic-like cell transplantation with nerve growth factor ameliorates motor dysfunction in a rat model of Parkinson's disease. Neurochem Res 2010a; 35: 15229.

Li SC, Tachiki LM, Luo J, Dethlefs BA, Chen Z, Loudon WG. A biological global positioning system: considerations for tracking stem cell behaviors in the whole body. Stem Cell Rev 2010b; 6: 317-33.

Lindvall O, Kokaia Z. Prospects of stem cell therapy for replacing dopamine neurons in Parkinson's disease. Trends Pharmacol Sci 2009; 30: 260-7.

Lindvall O, Kokaia Z. Stem cells in human neurodegenerative disorders--time for clinical translation? J Clin Invest 2010; 120: 29-40. 
Liu ZJ, Zhuge Y, Velazquez OC. Trafficking and differentiation of mesenchymal stem cells. J Cell Biochem 2009; 106: 984-91.

Lu L, Li F, Wang X. Novel anti-inflammatory and neuroprotective agents for Parkinson's disease. CNS Neurol Disord Drug Targets 2010; 9: 232-40.

Ma Y, Tang C, Chaly T, Greene P, Breeze R, Fahn S, et al. Dopamine cell implantation in Parkinson's disease: long-term clinical and (18)F-FDOPA PET outcomes. J Nucl Med 2010; 51: 7-15.

Madhavan L, Collier TJ. A synergistic approach for neural repair: cell transplantation and induction of endogenous precursor cell activity. Neuropharmacology 2010; 58: 83544.

Madhavan L, Daley BF, Paumier KL, Collier TJ. Transplantation of subventricular zone neural precursors induces an endogenous precursor cell response in a rat model of Parkinson's disease. J Comp Neurol 2009; 515: 102-15.

Magen I, Chesselet MF. Genetic mouse models of Parkinson's disease The state of the art. Prog Brain Res 2010; 184: 53-87.

Maguire-Zeiss KA, Federoff HJ. Future directions for immune modulation in neurodegenerative disorders: focus on Parkinson's disease. J Neural Transm 2010; 117: 1019-25.

Mathieu P, Battista D, Depino A, Roca V, Graciarena M, Pitossi F. The more you have, the less you get: the functional role of inflammation on neuronal differentiation of endogenous and transplanted neural stem cells in the adult brain. J Neurochem 2010; 112: 1368-85.

Matigian N, Abrahamsen G, Sutharsan R, Cook AL, Vitale AM, Nouwens A, et al. Diseasespecific, neurosphere-derived cells as models for brain disorders. Dis Model Mech 2010; 3: 785-98.

McCoy MK, Martinez TN, Ruhn KA, Wrage PC, Keefer EW, Botterman BR, et al. Autologous transplants of Adipose-Derived Adult Stromal (ADAS) cells afford dopaminergic neuroprotection in a model of Parkinson's disease. Exp Neurol 2008; 210: 14-29.

McGeer PL, Itagaki S, Boyes BE, McGeer EG. Reactive microglia are positive for HLA-DR in the substantia nigra of Parkinson's and Alzheimer's disease brains. Neurology 1988; 38: 1285-91.

McGeer PL, McGeer EG. Inflammation and the degenerative diseases of aging. Ann N Y Acad Sci 2004; 1035: 104-16.

McGeer PL, McGeer EG. Glial reactions in Parkinson's disease. Mov Disord 2008; 23: 474-83.

Meisner LF, Johnson JA. Protocols for cytogenetic studies of human embryonic stem cells. Methods 2008; 45: 133-41.

Meissner WG, Frasier M, Gasser T, Goetz CG, Lozano A, Piccini P, et al. Priorities in Parkinson's disease research. Nat Rev Drug Discov 2011; 10: 377-93.

Mendez I, Vinuela A, Astradsson A, Mukhida K, Hallett P, Robertson H, et al. Dopamine neurons implanted into people with Parkinson's disease survive without pathology for 14 years. Nat Med 2008; 14: 507-9.

Meyer AK, Maisel M, Hermann A, Stirl K, Storch A. Restorative approaches in Parkinson's Disease: which cell type wins the race? J Neurol Sci 2010; 289: 93-103. 
Miura K, Okada Y, Aoi T, Okada A, Takahashi K, Okita K, et al. Variation in the safety of induced pluripotent stem cell lines. Nat Biotechnol 2009; 27: 743-5.

Moloney TC, Rooney GE, Barry FP, Howard L, Dowd E. Potential of rat bone marrowderived mesenchymal stem cells as vehicles for delivery of neurotrophins to the Parkinsonian rat brain. Brain Res 2010; 1359: 33-43.

Muraoka K, Shingo T, Yasuhara T, Kameda M, Yuen WJ, Uozumi T, et al. Comparison of the therapeutic potential of adult and embryonic neural precursor cells in a rat model of Parkinson disease. J Neurosurg 2008; 108: 149-59.

Murrell W, Wetzig A, Donnellan M, Feron F, Burne T, Meedeniya A, et al. Olfactory mucosa is a potential source for autologous stem cell therapy for Parkinson's disease. Stem Cells 2008; 26: 2183-92.

Nagai M, Re DB, Nagata T, Chalazonitis A, Jessell TM, Wichterle H, et al. Astrocytes expressing ALS-linked mutated SOD1 release factors selectively toxic to motor neurons. Nat Neurosci 2007; 10: 615-22.

Neumann H, Kotter MR, Franklin RJ. Debris clearance by microglia: an essential link between degeneration and regeneration. Brain 2009; 132: 288-95.

Nikolic B, Faintuch S, Goldberg SN, Kuo MD, Cardella JF. Stem cell therapy: a primer for interventionalists and imagers. J Vasc Interv Radiol 2009; 20: 999-1012.

O'Keeffe GC, Barker RA, Caldwell MA. Dopaminergic modulation of neurogenesis in the subventricular zone of the adult brain. Cell Cycle 2009a; 8: 2888-94.

O'Keeffe GC, Tyers P, Aarsland D, Dalley JW, Barker RA, Caldwell MA. Dopamine-induced proliferation of adult neural precursor cells in the mammalian subventricular zone is mediated through EGF. Proc Natl Acad Sci U S A 2009b; 106: 8754-9.

Obeso JA, Rodriguez-Oroz MC, Benitez-Temino B, Blesa FJ, Guridi J, Marin C, et al. Functional organization of the basal ganglia: therapeutic implications for Parkinson's disease. Mov Disord 2008; 23 Suppl 3: S548-59.

Okano H, Sakaguchi M, Ohki K, Suzuki N, Sawamoto K. Regeneration of the central nervous system using endogenous repair mechanisms. J Neurochem 2007; 102: 1459-65.

Olanow CW, Goetz CG, Kordower JH, Stoessl AJ, Sossi V, Brin MF, et al. A double-blind controlled trial of bilateral fetal nigral transplantation in Parkinson's disease. Ann Neurol 2003; 54: 403-14.

Ourednik J, Ourednik V, Lynch WP, Schachner M, Snyder EY. Neural stem cells display an inherent mechanism for rescuing dysfunctional neurons. Nat Biotechnol 2002; 20: 1103-10.

Papanikolaou T, Lennington JB, Betz A, Figueiredo C, Salamone JD, Conover JC. In vitro generation of dopaminergic neurons from adult subventricular zone neural progenitor cells. Stem Cells Dev 2008; 17: 157-72.

Park HJ, Bang G, Lee BR, Kim HO, Lee PH. Neuroprotective effect of human mesenchymal stem cells in an animal model of double toxin-induced multiple system atrophyparkinsonism. Cell Transplant 2010.

Park HJ, Lee PH, Bang OY, Lee G, Ahn YH. Mesenchymal stem cells therapy exerts neuroprotection in a progressive animal model of Parkinson's disease. J Neurochem 2008a; 107: 141-51. 
Park IH, Arora N, Huo H, Maherali N, Ahfeldt T, Shimamura A, et al. Disease-specific induced pluripotent stem cells. Cell 2008b; 134: 877-86.

Park S, Koh SE, Maeng S, Lee WD, Lim J, Lee YJ. Neural progenitors generated from the mesenchymal stem cells of first-trimester human placenta matured in the hypoxicischemic rat brain and mediated restoration of locomotor activity. Placenta 2011; 32: 269-76.

Parkkinen L, Silveira-Moriyama L, Holton JL, Lees AJ, Revesz T. Can olfactory bulb biopsy be justified for the diagnosis of Parkinson's disease? Comments on "olfactory bulb alpha-synucleinopathy has high specificity and sensitivity for Lewy body disorders". Acta Neuropathol 2009; 117: 213-4; author reply 217-8.

Pasi CE, Dereli-Oz A, Negrini S, Friedli M, Fragola G, Lombardo A, et al. Genomic instability in induced stem cells. Cell Death Differ 2011.

Pavese N, Kiferle L, Piccini P. Neuroprotection and imaging studies in Parkinson's disease. Parkinsonism Relat Disord 2009; 15 Suppl 4: S33-7.

Perrier AL, Tabar V, Barberi T, Rubio ME, Bruses J, Topf N, et al. Derivation of midbrain dopamine neurons from human embryonic stem cells. Proc Natl Acad Sci U S A 2004; 101: 12543-8.

Piccini P, Brooks DJ, Bjorklund A, Gunn RN, Grasby PM, Rimoldi O, et al. Dopamine release from nigral transplants visualized in vivo in a Parkinson's patient. Nat Neurosci 1999; 2: 1137-40.

Picinich SC, Mishra PJ, Mishra PJ, Glod J, Banerjee D. The therapeutic potential of mesenchymal stem cells. Cell- \& tissue-based therapy. Expert Opin Biol Ther 2007; 7: 965-73.

Politis M, Piccini P. Brain imaging after neural transplantation. Prog Brain Res 2010; 184: 193-203.

Pruszak J, Isacson O. Molecular and cellular determinants for generating ES-cell derived dopamine neurons for cell therapy. Adv Exp Med Biol 2009; 651: 112-23.

Rascol O. "Disease-modification" trials in Parkinson disease: target populations, endpoints and study design. Neurology 2009; 72: S51-8.

Redmond DE, Jr., Weiss S, Elsworth JD, Roth RH, Wakeman DR, Bjugstad KB, et al. Cellular repair in the parkinsonian nonhuman primate brain. Rejuvenation Res 2010; 13: 188-94.

Roy NS, Cleren C, Singh SK, Yang L, Beal MF, Goldman SA. Functional engraftment of human ES cell-derived dopaminergic neurons enriched by coculture with telomerase-immortalized midbrain astrocytes. Nat Med 2006; 12: 1259-68.

Russo I, Barlati S, Bosetti F. Effects of neuroinflammation on the regenerative capacity of brain stem cells. J Neurochem 2011; 116: 947-56.

Sadan O, Bahat-Stromza M, Barhum Y, Levy YS, Pisnevsky A, Peretz H, et al. Protective effects of neurotrophic factor-secreting cells in a 6-OHDA rat model of Parkinson disease. Stem Cells Dev 2009; 18: 1179-90.

Schule B, Pera RA, Langston JW. Can cellular models revolutionize drug discovery in Parkinson's disease? Biochim Biophys Acta 2009; 1792: 1043-51.

Schwarz J, Storch A. Transplantation in Parkinson's disease: will mesenchymal stem cells help to reenter the clinical arena? Transl Res 2010; 155: 55-6. 
Schwarz SC, Schwarz J. Translation of stem cell therapy for neurological diseases. Transl Res 2011; 156: 155-60.

Serra PA, Pluchino S, Marchetti B, Desole MS, Miele E. The MPTP mouse model: cues on DA release and neural stem cell restorative role. Parkinsonism Relat Disord 2008; 14 Suppl 2: S189-93.

Shetty P, Ravindran G, Sarang S, Thakur AM, Rao HS, Viswanathan C. Clinical grade mesenchymal stem cells transdifferentiated under xenofree conditions alleviates motor deficiencies in a rat model of Parkinson's disease. Cell Biol Int 2009; 33: 830-8.

Shim JW, Park CH, Bae YC, Bae JY, Chung S, Chang MY, et al. Generation of functional dopamine neurons from neural precursor cells isolated from the subventricular zone and white matter of the adult rat brain using Nurr1 overexpression. Stem Cells 2007; 25: 1252-62.

Stroh A, Boltze J, Sieland K, Hild K, Gutzeit C, Jung T, et al. Impact of magnetic labeling on human and mouse stem cells and their long-term magnetic resonance tracking in a rat model of Parkinson disease. Mol Imaging 2009; 8: 166-78.

Tansey MG, Goldberg MS. Neuroinflammation in Parkinson's disease: its role in neuronal death and implications for therapeutic intervention. Neurobiol Dis 2010; 37: 510-8.

Thomas MG, Stone L, Evill L, Ong S, Ziman M, Hool L. Bone marrow stromal cells as replacement cells for Parkinson's disease: generation of an anatomical but not functional neuronal phenotype. Transl Res 2011; 157: 56-63.

Tonnesen J, Parish CL, Sorensen AT, Andersson A, Lundberg C, Deisseroth K, et al. Functional integration of grafted neural stem cell-derived dopaminergic neurons monitored by optogenetics in an in vitro Parkinson model. PLoS One 2011; 6: e17560.

Toriumi H, Yoshikawa M, Matsuda R, Nishimura F, Yamada S, Hirabayashi H, et al. Treatment of Parkinson's disease model mice with allogeneic embryonic stem cells: necessity of immunosuppressive treatment for sustained improvement. Neurol Res 2009; 31: 220-7.

Ungerstedt U. 6-Hydroxy-dopamine induced degeneration of central monoamine neurons. Eur J Pharmacol 1968; 5: 107-10.

Van Kampen JM, Eckman CB. Dopamine D3 receptor agonist delivery to a model of Parkinson's disease restores the nigrostriatal pathway and improves locomotor behavior. J Neurosci 2006; 26: 7272-80.

van Nuenen BF, van Eimeren T, van der Vegt JP, Buhmann C, Klein C, Bloem BR, et al. Mapping preclinical compensation in Parkinson's disease: an imaging genomics approach. Mov Disord 2009; 24 Suppl 2: S703-10.

Venkataramana NK, Kumar SK, Balaraju S, Radhakrishnan RC, Bansal A, Dixit A, et al. Open-labeled study of unilateral autologous bone-marrow-derived mesenchymal stem cell transplantation in Parkinson's disease. Transl Res 2010; 155: 62-70.

Vicente Miranda H, Outeiro TF. The sour side of neurodegenerative disorders: the effects of protein glycation. J Pathol 2010; 221: 13-25.

Vierbuchen T, Ostermeier A, Pang ZP, Kokubu Y, Sudhof TC, Wernig M. Direct conversion of fibroblasts to functional neurons by defined factors. Nature 2010; 463: 1035-41.

Wakeman DR, Dodiya HB, Kordower JH. Cell transplantation and gene therapy in Parkinson's disease. Mt Sinai J Med 2011; 78: 126-58. 
Wang F, Yasuhara T, Shingo T, Kameda M, Tajiri N, Yuan WJ, et al. Intravenous administration of mesenchymal stem cells exerts therapeutic effects on parkinsonian model of rats: focusing on neuroprotective effects of stromal cellderived factor-1alpha. BMC Neurosci 2010; 11: 52.

Weissman IL. Translating stem and progenitor cell biology to the clinic: barriers and opportunities. Science 2000; 287: 1442-6.

Wernig M, Zhao JP, Pruszak J, Hedlund E, Fu D, Soldner F, et al. Neurons derived from reprogrammed fibroblasts functionally integrate into the fetal brain and improve symptoms of rats with Parkinson's disease. Proc Natl Acad Sci U S A 2008; 105 : 5856-61.

White RB. Looks like a duck, quacks like a duck ... still behaves like a bone marrow stromal cell. Transl Res 2011; 157: 53-5.

Whitton PS. Neuroinflammation and the prospects for anti-inflammatory treatment of Parkinson's disease. Curr Opin Investig Drugs 2010; 11: 788-94.

Winner B, Desplats P, Hagl C, Klucken J, Aigner R, Ploetz S, et al. Dopamine receptor activation promotes adult neurogenesis in an acute Parkinson model. Exp Neurol 2009; 219: 543-52.

Winner B, Geyer M, Couillard-Despres S, Aigner R, Bogdahn U, Aigner L, et al. Striatal deafferentation increases dopaminergic neurogenesis in the adult olfactory bulb. Exp Neurol 2006; 197: 113-21.

Wu Y, Le W, Jankovic J. Preclinical biomarkers of Parkinson disease. Arch Neurol 2011; 68: 22-30.

Xu L, Tan YY, Ding JQ, Chen SD. The iPS technique provides hope for Parkinson's disease treatment. Stem Cell Rev 2010a; 6: 398-404.

Xu Q, Jiang X, Ke Y, Zhang S, Xu R, Zeng Y. Gene therapy in hemiparkinsonian rhesus monkeys: long-term survival and behavioral recovery by transplantation of autologous human tyrosine hydroxylase-expressing neural stem cells. Cytotherapy 2010b; 12: 226-37.

Yang JR, Liao CH, Pang CY, Huang LL, Lin YT, Chen YL, et al. Directed differentiation into neural lineages and therapeutic potential of porcine embryonic stem cells in rat Parkinson's disease model. Cell Reprogram 2010; 12: 447-61.

Yasuhara T, Matsukawa N, Hara K, Yu G, Xu L, Maki M, et al. Transplantation of human neural stem cells exerts neuroprotection in a rat model of Parkinson's disease. J Neurosci 2006; 26: 12497-511.

Yoshimi K, Ren YR, Seki T, Yamada M, Ooizumi H, Onodera M, et al. Possibility for neurogenesis in substantia nigra of parkinsonian brain. Ann Neurol 2005; 58: 31-40.

Zhang S, Zou Z, Jiang X, Xu R, Zhang W, Zhou Y, et al. The therapeutic effects of tyrosine hydroxylase gene transfected hematopoetic stem cells in a rat model of Parkinson's disease. Cell Mol Neurobiol 2008; 28: 529-43.

Zhao C, Deng W, Gage FH. Mechanisms and functional implications of adult neurogenesis. Cell 2008; 132: 645-60.

Zhu Q, Ma J, Yu L, Yuan C. Grafted neural stem cells migrate to substantia nigra and improve behavior in Parkinsonian rats. Neurosci Lett 2009; 462: 213-8. 
Zou Z, Jiang X, Zhang W, Zhou Y, Ke Y, Zhang S, et al. Efficacy of Tyrosine Hydroxylase gene modified neural stem cells derived from bone marrow on Parkinson's disease-a rat model study. Brain Res 2010; 1346: 279-86. 


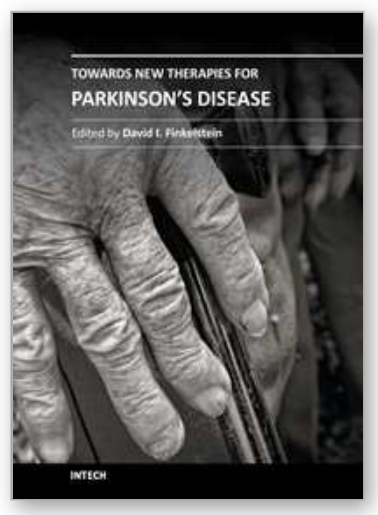

\section{Towards New Therapies for Parkinson's Disease}

Edited by Prof. David Finkelstein

ISBN 978-953-307-463-4

Hard cover, 396 pages

Publisher InTech

Published online 02, November, 2011

Published in print edition November, 2011

Parkinson's disease (PD) is characterised clinically by various non-motor and progressive motor symptoms, pathologically by loss of dopamine producing cells and intraneuronal cytoplasmic inclusions composed primarily of ?-synuclein. By the time a patient first presents with symptoms of Parkinson's disease at the clinic, a significant proportion of the cells in the substantia nigra have already been destroyed. This degeneration progresses despite the current therapies until the cell loss is so great that the quality of normal life is compromised. The dopamine precursor levodopa is the most valuable drug currently available for the treatment of PD. However for most PD patients, the optimal clinical benefit from levodopa decreases around five to six years of treatment. The aim of the chapters of this book is to work towards an understanding in the mechanisms of degeneration and to develop disease modifying therapies.

\section{How to reference}

In order to correctly reference this scholarly work, feel free to copy and paste the following:

Lidia Cova and Marie-Therese Armentero (2011). 1980-2011: Parkinson's Disease and Advance in Stem Cell Research, Towards New Therapies for Parkinson's Disease, Prof. David Finkelstein (Ed.), ISBN: 978-953-307463-4, InTech, Available from: http://www.intechopen.com/books/towards-new-therapies-for-parkinson-sdisease/1980-2011-parkinson-s-disease-and-advance-in-stem-cell-research

\section{INTECH}

open science | open minds

\author{
InTech Europe \\ University Campus STeP Ri \\ Slavka Krautzeka 83/A \\ 51000 Rijeka, Croatia \\ Phone: +385 (51) 770447 \\ Fax: +385 (51) 686166 \\ www.intechopen.com
}

\author{
InTech China \\ Unit 405, Office Block, Hotel Equatorial Shanghai \\ No.65, Yan An Road (West), Shanghai, 200040, China \\ 中国上海市延安西路65号上海国际贵都大饭店办公楼 405 单元 \\ Phone: +86-21-62489820 \\ Fax: +86-21-62489821
}


(C) 2011 The Author(s). Licensee IntechOpen. This is an open access article distributed under the terms of the Creative Commons Attribution 3.0 License, which permits unrestricted use, distribution, and reproduction in any medium, provided the original work is properly cited. 